\title{
Optimization of Electromagnetic Modules on Graphical Braille Screen for Visual Impaired People
}

\author{
DIMITAR KARASTOYANOV ${ }^{1}$, IVAN YATCHEV ${ }^{2}$ \\ ${ }^{1}$ Institute of Information and Communication Technologies \\ Bulgarian Academy of Sciences \\ bl. 2, ac. G. Bonchev str., Sofia 1113 \\ BULGARIA \\ ${ }^{2}$ Faculty of Electrical Engineering \\ Technical University - Sofia \\ 8 Kl. Ohridski Blvd, Sofia 1000 \\ BULGARIA
}

\begin{abstract}
The paper presents an approach to investigate the effect of different design parameters on the static "force_travel" characteristics and the magnetic field distribution of patented variants of an electromagnetic module for a Braille screen..
\end{abstract}

Key-Words: - Electromagnetic devices, Magnetic circuits, Micro actuators, Design optimization.

Received: March 24, 2021. Revised: September 10, 2021. Accepted: September 13, 2021. Published: September 16, 2021

\section{Introduction}

Increasing demands for improving the living conditions and quality of life of people and new modern materials and technologies are a prerequisite for seeking new opportunities to receive more information from visually impaired people. Such an opportunity is provided by the so-called Braille screens - the subject of research by many authors [1]-[3].

During the last decade, a number of touch screen devices for visually impaired users have been announced, as follows:

Graphiti - an Interactive Tactile Graphics Display based on Tactuator technology [4]. It has an array of $60 \times 40$ moving pins. Each pin is independently addressable.

BlindPAD - an interactive tactile tablet that can display in real time maps, graphics, and other symbols [5]. The tablet has $12 \times 16$ independently controlled pins. The tablet has $200 \mathrm{mN}$ holding force.

HyperBraille - in the opinion of the authors is the best tactile graphics display at present [6]. It is a graphics-enabled laptop with 9,000 pin-matrix appeared in 2008. The display is touch-sensitive so the user can locate the cursor position. Ac-cording to [7], in 2015 the model with a pin-matrix of 7,200 dots, arranged in a 120x60 array, costed about $\$ 56,000$.

In [8] a prototype of a Graphical Braille Display is proposed. The Braille Display represents a matrix, comprised of a base with actuators - fixed linear electromagnetic micro drives.

In a series of previous works, [9]-[11], the possibilities of using as basic elements for construction of a Braille screen with reduced consumption of polarized actuating magnets are considered. They investigate the influence of different geometric parameters on their basic characteristics under different operating modes. The results obtained show that their performance generally depends on two main indicators - the force of departure from the extreme lower position and the force of retention in the extreme upper position. It is of interest to investigate the possibilities for improving them (reducing the permanent magnet holding force in the lower position and increasing the starting force from this position

\section{Research and Development}

Electromagnetic drive structures are being studied, Fig. 1. The mover is a permanent magnet. The upper and lower coil (windings) are connected in series. This connection is constructed so that the flux created by each of them is in opposite directions in the mover zone. By choosing the proper power supply polarity, the motion of the mover will be in desired direction. Additional construction variants of the actuator have also been considered, in which two small ferromagnetic discs are placed on both sides - upper and lower - of the moving permanent 
magnet. This actuator is also energy efficient, as energy is used only for changing the position of the moving part from lower to upper and vice versa. Both at lower and at upper position, no energy is used. At these positions, the mover is kept fixed due the force ensured by the permanent magnet (sticks to the core), [12].
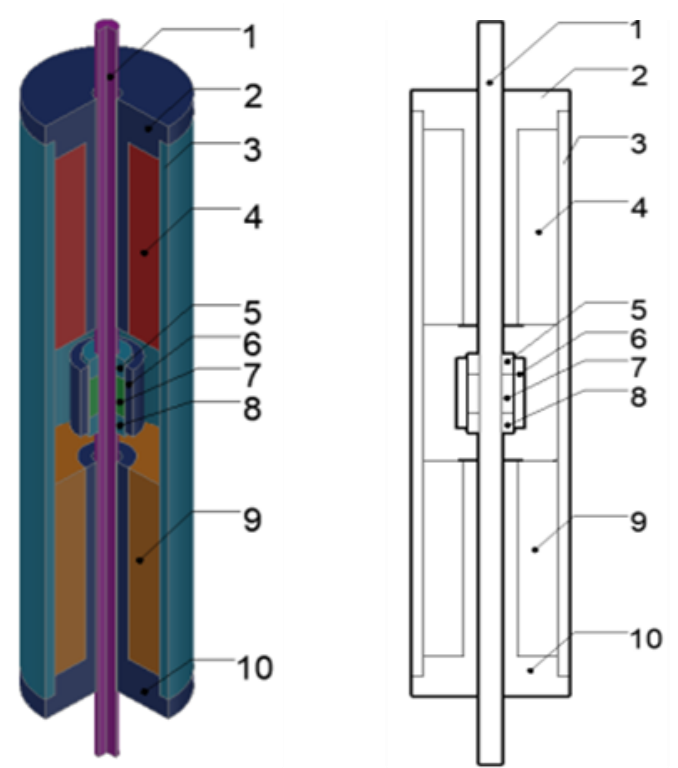

Fig. 1: General view of electromagnetic module for Braille screen: 1 - axis; 2 and 10 - magnetic cores; 3 - external magnetic conductor; 4 and 9 - control windings; 5 and 8- ferromagnetic washers; 6 - nonmagnetic sleeve; 7 - permanent magnet.

In the most general case, they contain an external magnetic core (conductor), control coils with magnetic circuits (lower and upper kernel) and an anchor, which is an axially magnetized permanent magnet with ferromagnetic washers and nonmagnetic axes on both sides. The actuation to the two end positions is carried out by means of electrical impulses applied to the control coils, and the holding of the anchor in the end positions (upper and lower) is by a permanent magnet.

We consider the development of three variants of the Braille Screen / Display for visually impaired people:

- Small, up to $24 \times 16$ pins. It will be used by children in schools for exploring simple graphics, Fig. 2;

- Average, up to $48 \times 32$ pins. It will be used by visually impaired users when working with computers and graphical interface - Windows icons;

- Large, up to 128x96 pins and more. These displays will be designed for museums and galleries. They will present the cultural and historical heritage - paintings, tapestries, icons.
The studies are performed by modeling using the finite element method (FEMM computer program), with a Maxwell stress tensor approach to calculate the force and an algorithm developed to determine the "force-travel" characteristics and the magnetic field distribution for different positions of the anchor and different power modes of the control coils, for different designs. The geometrical parameters of the linear electromagnetic micro drives are optimized.

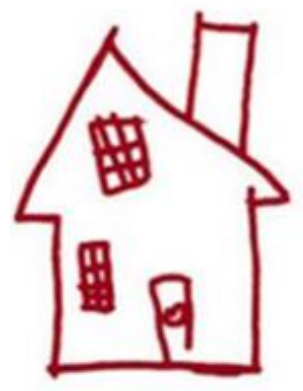

Fig. 2a: Drawing on the Braille screen:

User drawings can be shown with lines similar the original.

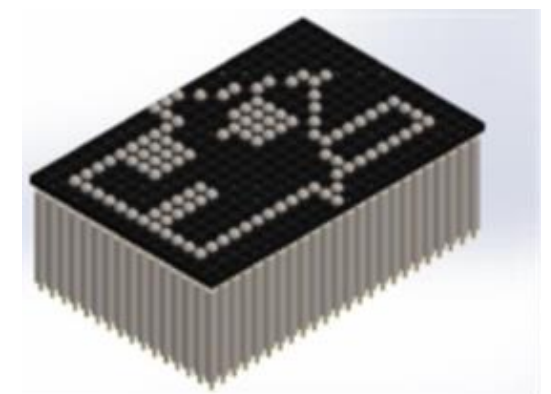

Fig. 2b: Drawing on the Braille screen:

A view of user-generated content with resolution 16x20 pins.

\section{Optimization of the Braille Screen Modules}

We have conducted research and development to improve the performance of patented versions of electromagnetic modules for Braille Display, [9][11]:

\subsection{Study of a Variant with a Conical Lower Washer and a Flat Lower Core}

The investigated construction is shown in Fig. 3. It is characterized by the presence of a bevel at a certain angle on the inner surface of the lower washer.

The tests were performed for different bevel angles and different current densities at the following sizes of the individual components: 
- free stroke of the movable part $-1.5 \mathrm{~mm}$;

- height of the windings Hcoil - $10 \mathrm{~mm}$;

- outer radius of the module Rout - $2.5 \mathrm{~mm}$;

- height of the permanent magnet Hmag $-2 \mathrm{~mm}$;

- height of the upper washer HdiskUP -1 mm;

- height of the lower washer HdiskDOWN -1 $\mathrm{mm}$.

The obtained static characteristics are respectively - in th

Characteristics force-displacement (travel) are made at current density $\mathrm{J}=0,5,10$ and $20 \mathrm{~A} / \mathrm{mm} 2$ and different angles Adown $=0,10,20,30,40,50$ and $60 \mathrm{deg}$. of the bevel of the lower washer.

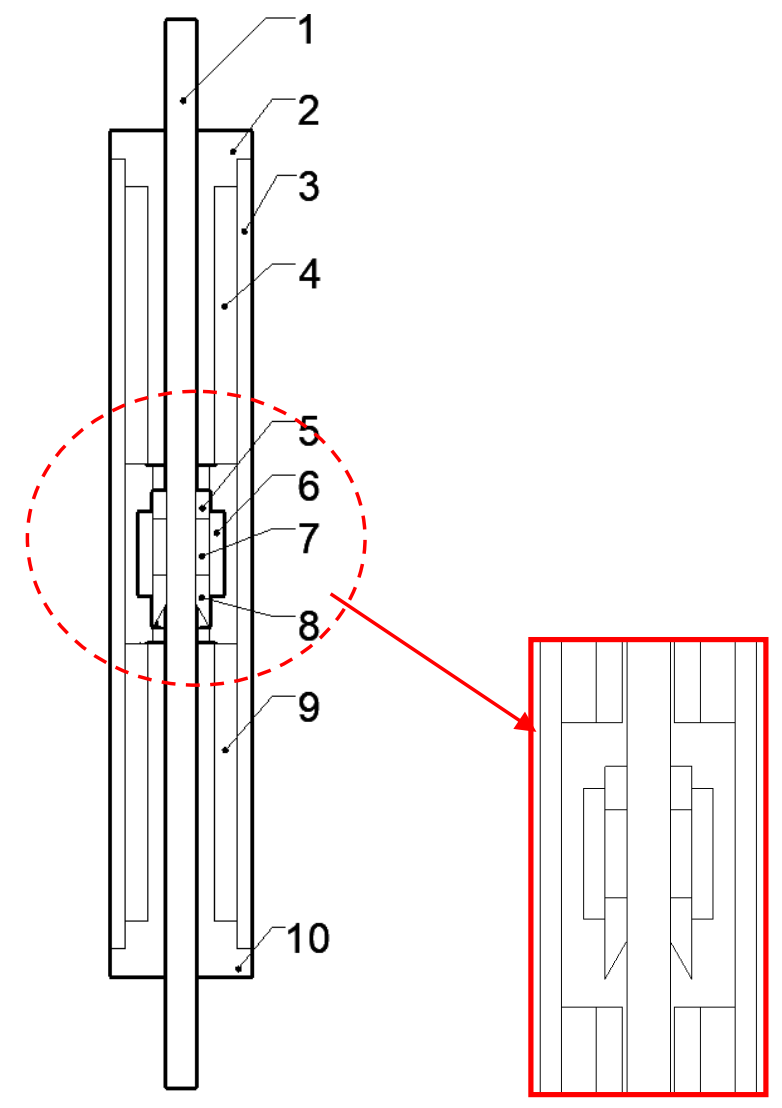

Fig. 3: Construction with conical lower washer and flat lower core: 1 - axis; 2 - upper core; 3 - external magnetic conductor; 4 and 9 - control windings; 5upper flat ferromagnetic washer; 6 - non-magnetic sleeve; 7 - permanent magnet; 8 - lower conical ferromagnetic washer; 10 - lower flat core

The main advantage of the design is that the movement of the needles (axes) from the extreme lower position requires low power consumption due to the reduced contact area between the cylindrical axially magnetized permanent magnet with a lower ferromagnetic washer tapered on the inside and the lower flat magnetic core, [13].

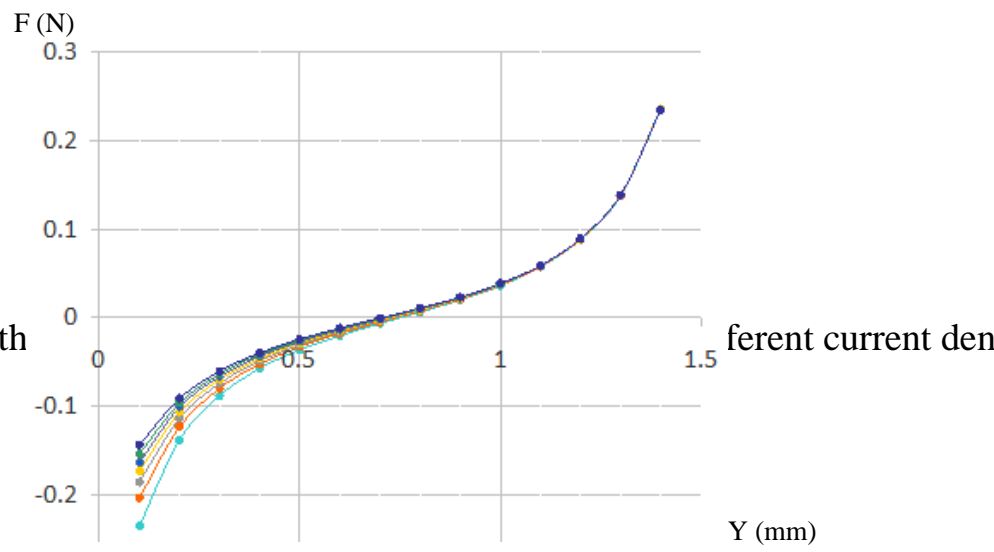

Fig. 4: Characteristics force-displacement: $\mathrm{J}=0$ $\mathrm{A} / \mathrm{mm}^{2}$, Adown $=0-60 \mathrm{deg}$.

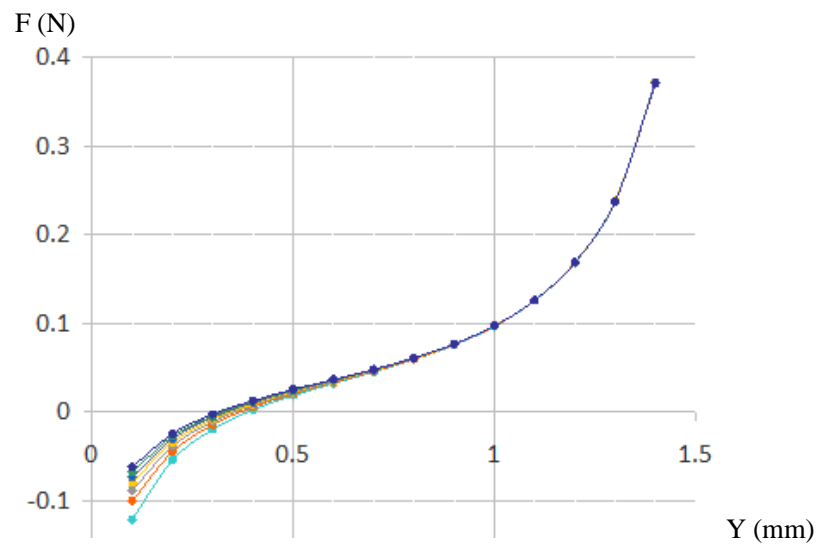

Fig. 5: Characteristics force-displacement: $\mathrm{J}=5$ $\mathrm{A} / \mathrm{mm} 2$, Adown $=0-60 \mathrm{deg}$.

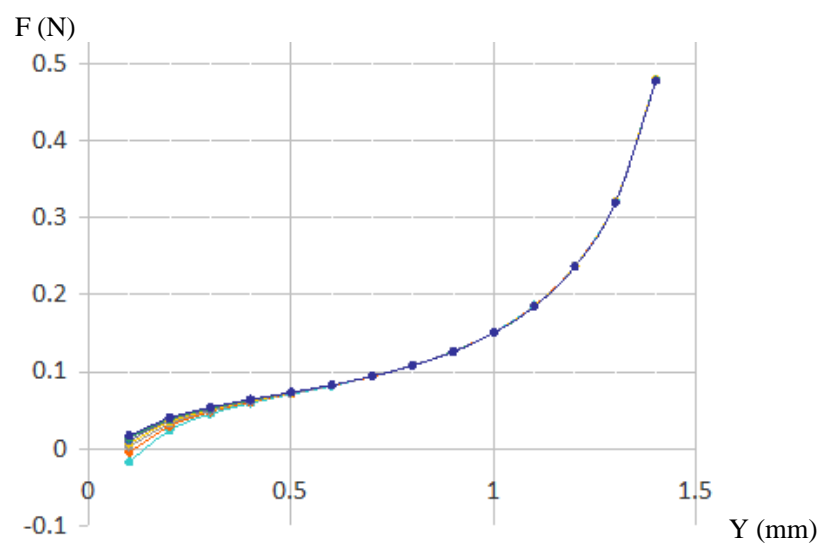

Fig. 6: Characteristics force-displacement: $J=10$ $\mathrm{A} / \mathrm{mm} 2$, Adown $=0-60 \mathrm{deg}$. 


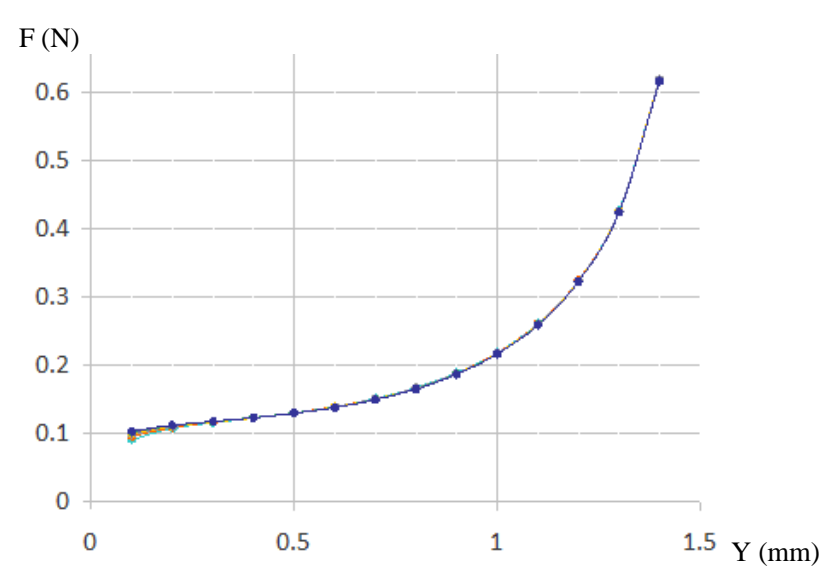

Fig. 7: Characteristics force-displacement: $\mathrm{J}=20$ $\mathrm{A} / \mathrm{mm}^{2}$, Adown $=0-60 \mathrm{deg}$.

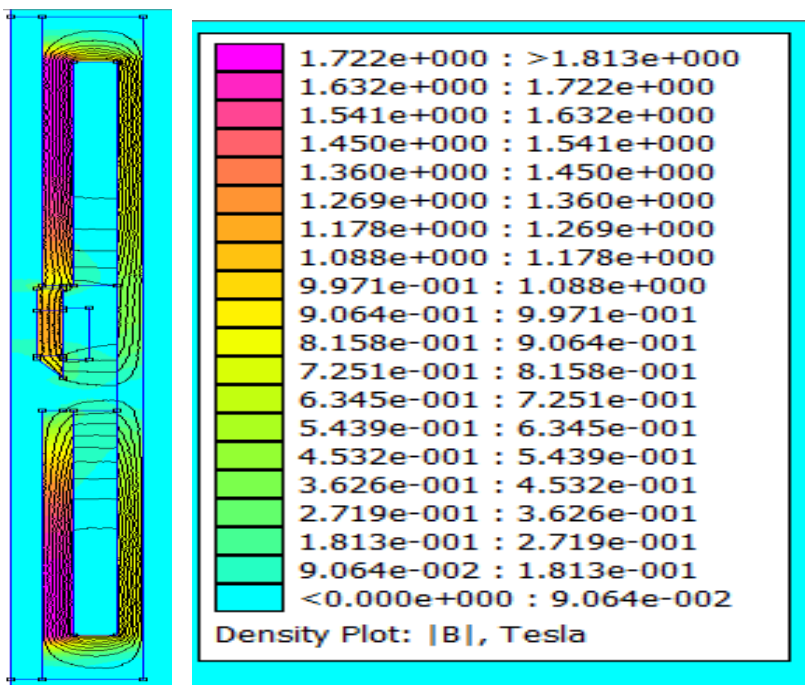

Fig. 8: The distribution of the magnetic field for lower positions of the anchor

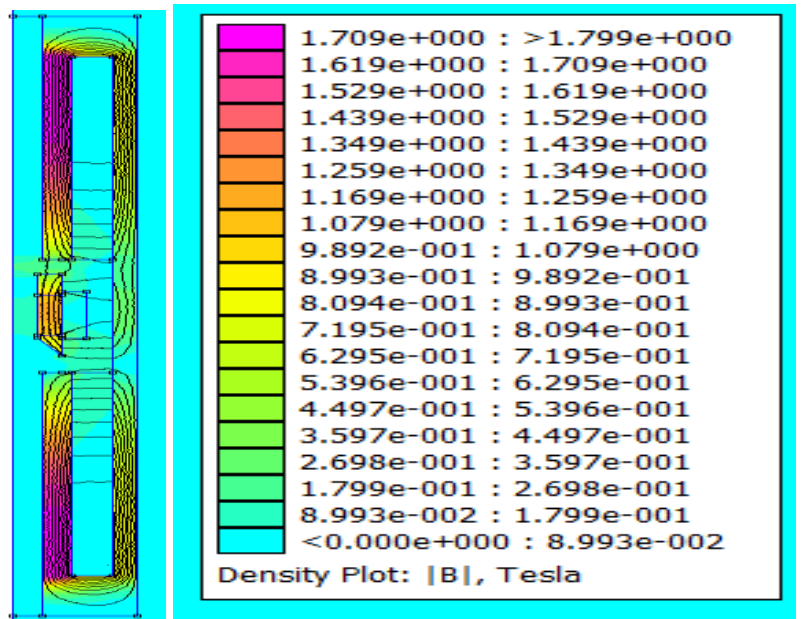

Fig. 9: The distribution of the magnetic field for neutral positions of the anchor

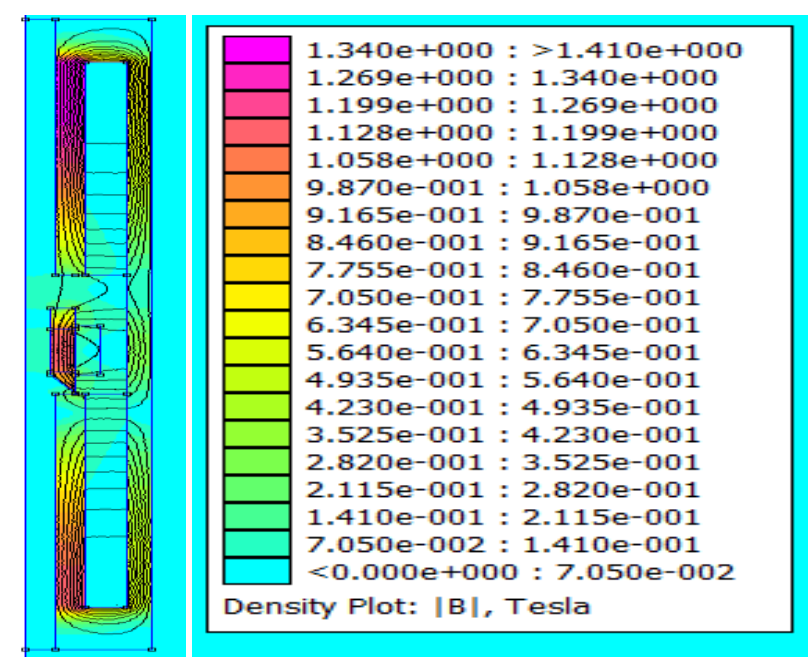

Fig. 10: The distribution of the magnetic field for upper positions of the anchor

\subsection{Examination of a Variant with a Flat Lower Washer and a Beveled Inner Surface of the Lower Core}

The investigated construction is shown in Fig. 11. It is characterized by the presence of a bevel at a certain angle on the inner surface of the upper part of the lower core.

The tests were performed for different bevel angles and different current densities at the following sizes of the individual components:

- free stroke of the movable part $-1.5 \mathrm{~mm}$;

- height of the windings Hcoil - $10 \mathrm{~mm}$;

- outer radius of the module Rout - $2.5 \mathrm{~mm}$;

- height of the permanent magnet Hmag -2 mm;

- height of the upper washer HdiskUP -1 mm;

- height of the lower washer HdiskDOWN -1 $\mathrm{mm}$.

The obtained static characteristics are respectively - in the absence of power supply in Fig. 12 and at different current densities - in Fig. 13, 14 and 15. The distribution of the magnetic field for different positions of the anchor is shown in Fig. 16, 17 and 18.

Characteristics force-displacement (travel) are made at current density $\mathbf{J}=0,5,10$ and $20 \mathrm{~A} / \mathrm{mm} 2$ and different angles Adown $=0,10,20,30,40,50$ and $60 \mathrm{deg}$. of the bevel of the lower magnetic core.

The main advantage of the design is that the movement of the needles (axes) from the extreme lower position requires low power consumption due to the reduced contact area between the cylindrical axially magnetized permanent magnet with a lower flat ferromagnetic washer and the lower magnetic core tapered on the inside, [14]. 


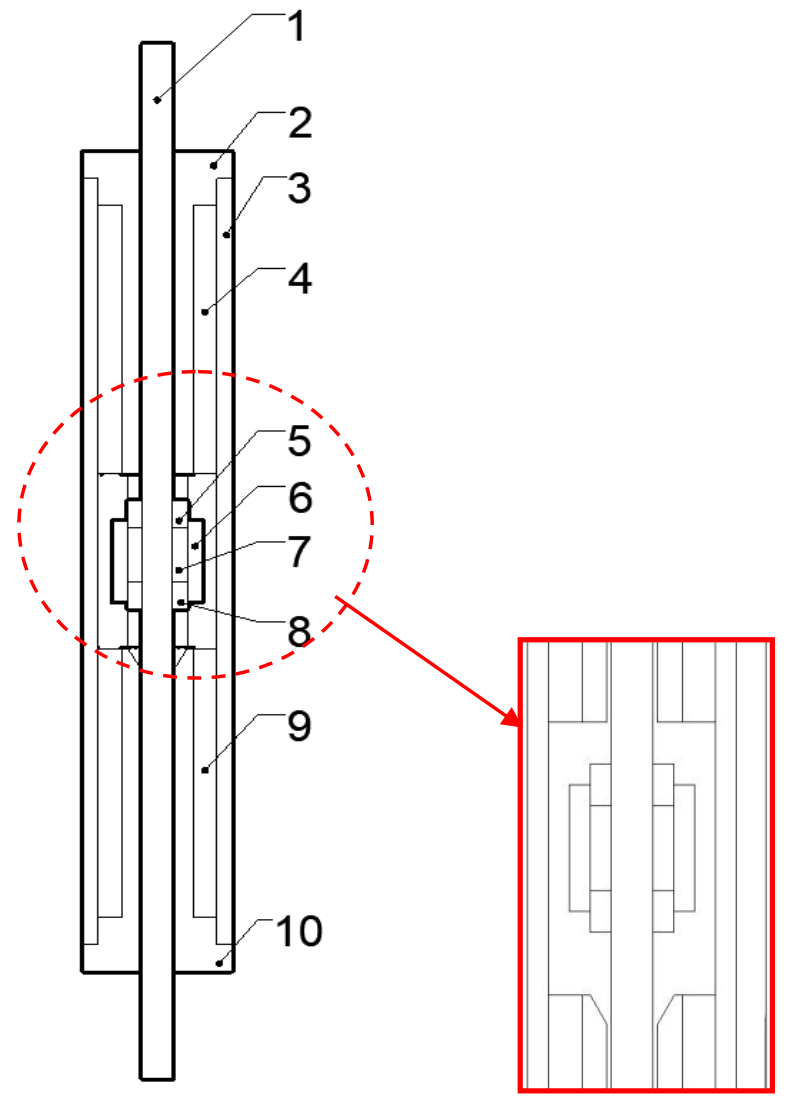

Fig. 11: Construction with flat lower washer and conical lower core: 1 - axis; 2 - upper core; 3 external magnetic conductor; 4 and 9 - control windings; 5- upper flat ferromagnetic washer; 6 non-magnetic sleeve; 7 - permanent magnet; 8 lower flat ferromagnetic washer; 10 - lower conical core.

\section{$\mathrm{F}(\mathrm{N})$}

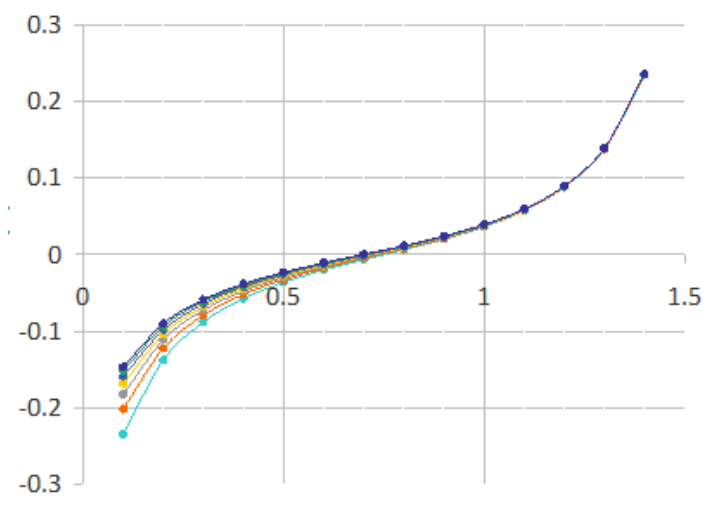

$\mathrm{Y}(\mathrm{mm})$

Fig. 12: Characteristics force-displacement: $\mathrm{J}=0$ $\mathrm{A} / \mathrm{mm} 2$, Adown $=0-60 \mathrm{deg}$.
$\mathrm{F}(\mathrm{N})$

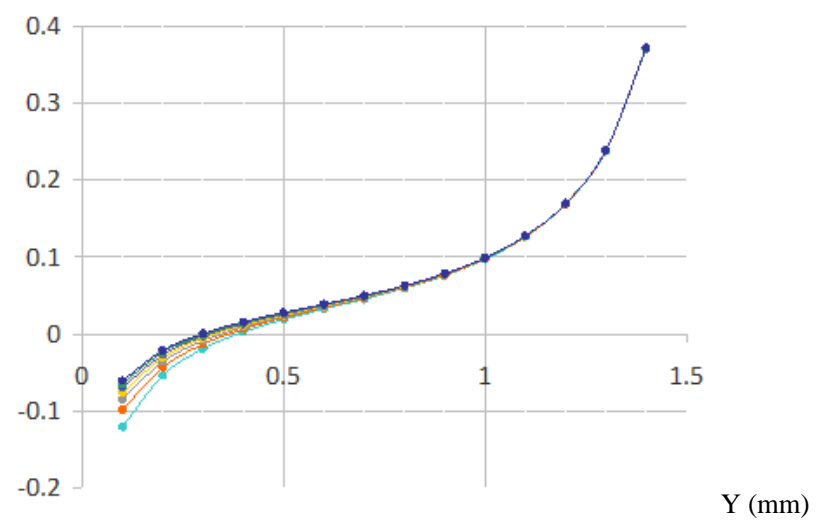

Fig. 13: Characteristics force-displacement: $J=5$ $\mathrm{A} / \mathrm{mm} 2$, Adown $=0-60$ deg.

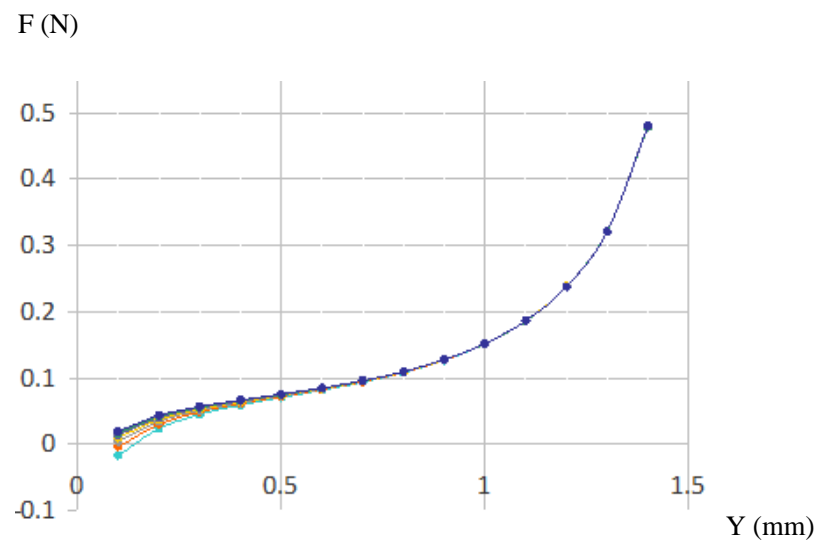

Fig. 14: Characteristics force-displacement: $\mathrm{J}=10$ $\mathrm{A} / \mathrm{mm} 2$, Adown $=0-60 \mathrm{deg}$.

$\mathrm{F}(\mathrm{N})$

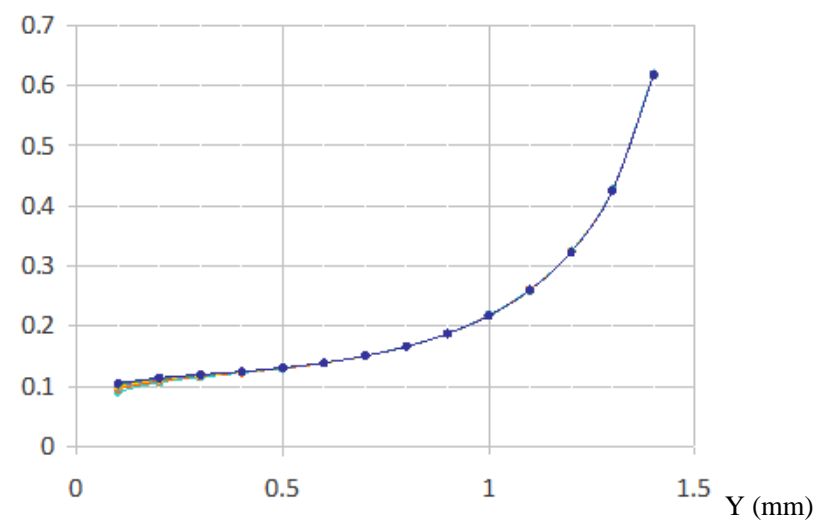

Fig. 15: Characteristics force-displacement: $\mathrm{J}=20$ $\mathrm{A} / \mathrm{mm} 2$, Adown $=0-60 \mathrm{deg}$. 


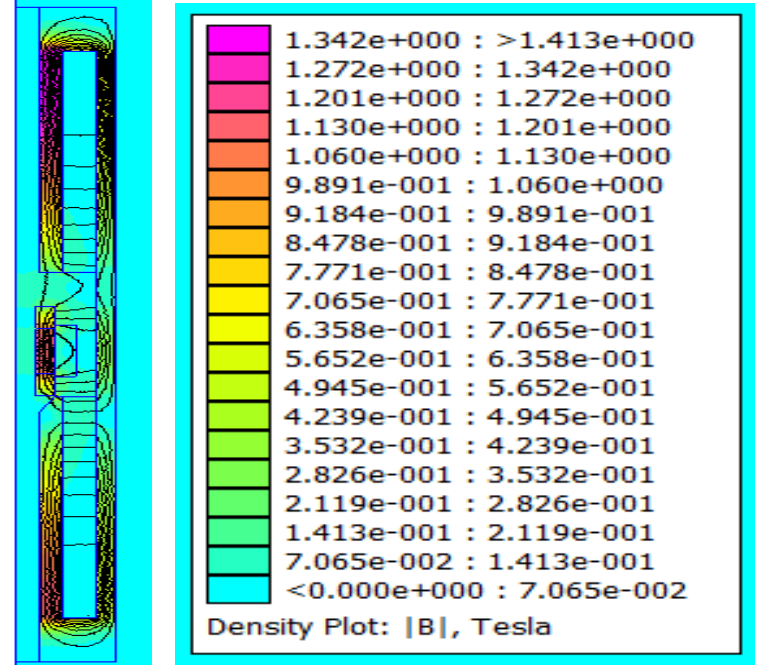

Fig. 16: The distribution of the magnetic field for lower positions of the anchor

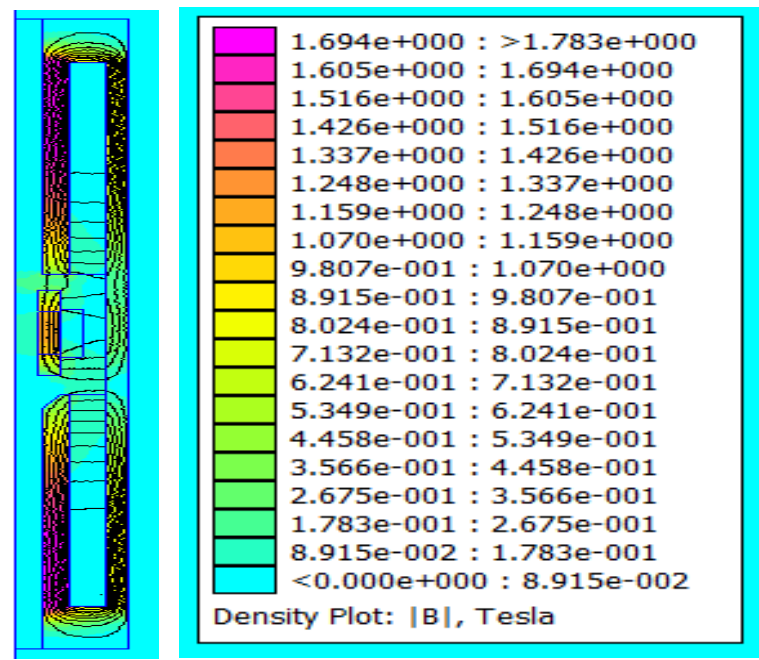

Fig. 17. The distribution of the magnetic field for neutral positions of the anchor

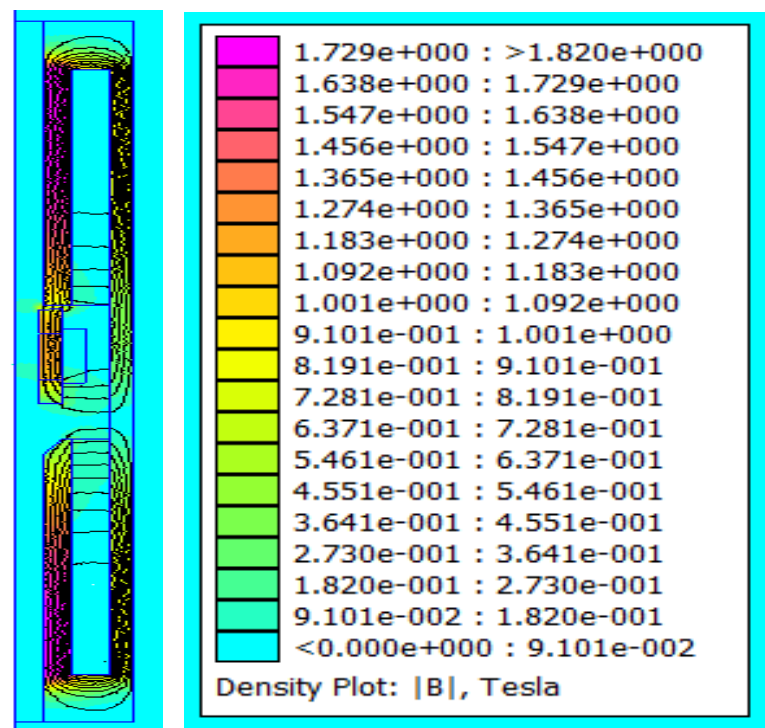

Fig. 18. The distribution of the magnetic field for upper positions of the anchor

\section{Conclusion}

The analysis of the obtained results shows that the best possibilities for improving the power-stroke characteristics of the linear electromagnetic micro drives are provided by the construction of Fig. 11. It allows to reduce the holding force of the anchor in the lower position, which in turn can be expected to improve the dynamic characteristics of the system. The use of a permanent magnet with a hole will also contribute to the latter, which will allow the use of an entire non-magnetic axis. As a result, the mass of the anchor will be reduced due to the elimination of the need to use the fixing non-magnetic sleeve, which will not only improve the dynamic characteristics, but also increase the holding force in the uppermost position of the anchor. The use of a permanent magnet with a hole and a whole nonmagnetic axis will allow both to simplify the design of the modules and to improve its manufacturability.

The main benefit of this research and development is that a permanent magnet with a hole is used, combined with a reduced contact area in the lower position - through a conical lower washer or a beveled lower core. This requires less force to move from a lower position, which is associated with lower energy consumption. Energy efficiency is significantly increased for a Braille display with multiple linear electromagnetic micro motors - for example $90 \times 60=5400$.

\section{Acknowledgments:}

The paper is supported by the Bulgarian National Science Fund Grants No DN 17/21-2017 and No DN 17/13-2017.

\section{References:}

[1] Chaves D., I. Peixoto, A.C.O. Lima, M. Vieira, C.J. de Araujo, Microtuators of SMA for Braille display system, IEEE International Workshop on Medical Measurements and Applications. MeMeA 2009, pp. 64-68.

[2] Kwon H.-J., S. W. Lee, S.S. Lee, Braille code display device with a PDMS membrane and thermopneumatic actuator, 21st IEEE International Conference on Micro Electro Mechanical Systems MEMS 2008, pp. 527-530.

[3] Kawaguchi Y., K. Ioi, Y. Ohtsubo, Design of new Braille display using inverse principle of tuned mass damper, Proceedings of SICE Annual Conference 2010, pp. 379-383.

[4] Orbit Research, Orbit Reader 20: Revolutionary Technology - A Breakthrough in Affordability Highest Quality Braille at the Lowest Price, URL: 
http://www.orbitresearch.com/ , last accessed 2018/02/28.

[5] Personal Assistive Device for BLIND and visually impaired people (BlindPAD), FP7ICT-2013-10 Project, Grant No 611621, Final Project Report, v. 5 October 2017, URL: https://www.blindpad.eu/ , last accessed 2018/02/28.

[6] Bornschein, J., Prescher, D. \& Weber, G., Inclusive Production of Tactile Graphics. INTERACT (1), 2015, pp. 80-88, (2015)

[7] o'Modhrain, S., Giudice, N. A., Gardner, J.A. \& Legge, G.E., Designing Media for VisuallyImpaired Users of Refreshable Touch Displays: Possibilities and Pitfalls. IEEE Transactions on Haptics 8(3), pp. 248-257, (2015)

[8] Karastoyanov D., Innovative graphical braille screen for visually impaired people. In: Studies in Computational Intelligence 648, Springer International Publishing, pp. 219-240, DOI: 10.1007/978-3-319-32207-0_14, (2016)

[9] Karastoyanov D., Yatchev I., Hinov K., Rachev T., Braille screen., BG patent 66562 B1, 2016

[10] Karastoyanov D., Yatchev I., Hinov K., Balabozov Y., Braille display., $B G$ patent 66702 B1, 2017

[11] Karastoyanov D., Yatchev I., Hinov K., Balabozov Y., Braille display., $B G$ patent 66734 B1, 2018

[12] Gyoshev S., Karastoyanov D., Stoimenov N., Cantoni V., Lombardi L., Setti A.. Exploiting a Graphical Braille Display for Art Masterpieces. Computers Helping People with Special Needs, 2, 10897, Springer, 2018, ISBN:978-3-31994273-5, ISSN:0302-9743, DOI:10.1007/9783-319-94274-2, 237-245.

[13] Karastoyanov D., Yatchev I., Balabozov Y., Braille display., BG patent application, Reg No 113203 / 9.9.2020

[14] Karastoyanov D., Yatchev I., Balabozov Y., Braille display., $B G$ patent application, Reg No 113204 / 9.9.2020

\section{Contribution of Individual Authors to the Creation of a Scientific Article (Ghostwriting Policy) \\ Dimitar Karastoyanov has organized and executed the experiments. \\ Ivan Yatchev has organized the simulation and the optimization.}

\section{Sources of Funding for Research Presented in a Scientific Article or Scientific Article Itself}

The paper is supported by the Bulgarian National Science Fund Grants No DN 17/21-2017 and No DN 17/13-2017.

\section{Creative Commons Attribution License 4.0 (Attribution 4.0 International, CC BY 4.0)}

This article is published under the terms of the Creative Commons Attribution License 4.0 https://creativecommons.org/licenses/by/4.0/de ed.en US 